\title{
ГИБКИЕ ТЕХНОЛОГИИ УПРАВЛЕНИЯ: ИННОВАЦИОННЫЙ ДИСКУРС КЛАССИФИКАЦИОННЫХ ПРИЗНАКОВ
}

\author{
(C) 2020 Шестакова Елена Валерьевна \\ доктор экономических наук, доцент \\ заведующий кафедрой управления персоналом, сервиса и туризма \\ Оренбургский государственный университет, Россия, Оренбург \\ E-mail:shestakovaev56@gmail.com
}

\section{(C) 2020 Ситжанова Акжан Мурзагуловна}

кандидат экономических наук, доцент кафедры управления персоналом, сервиса и туризма

Оренбургский государственный университет, Россия, Оренбург

E-mail: sithanovak@bk.ru

\section{(c) 2020 Прытков Ринад Михайлович}

старший преподаватель кафедры управления персоналом, сервиса и туризма

Оренбургский государственный университет, Россия, Оренбург

E-mail: r.prytkov@mail.ru

Гибкие технологии управления - это система целей, средств и методов обеспечения контроля над предприятием. Технология - это инструмент влияния, использование которого может быть доверено различным руководителям структурных подразделений предприятия. Именно поэтому так важно классифицировать технологии и определить диапазон их применения.

К сферам проектного управления относятся финансовая, кадровая, структурная сфера деятельности организации. И для того, чтобы все эти области были широко и правильно охвачены, команда, работающая над проектом, должна правильно распределить свои обязанности, чему и способствует гибкая методология управления проектами. В статье представлены основные принципы Agile, выделены основные характеристики методологии Agile, их преимущества и недостатки. Разработана классификация гибких технологии управления.

Ключевые слова: технология, проектный менеджмент, гибкие технологии, принцип гибкости, классификация гибких технологий, методологии Agile.

В настоящее время технология - это наука о производстве, если быть более точнее это наука о наиболее экономичных способах и процессах переработки сырья и материалов в средства производства и потребительские товары. Производить и перерабатывать сырьё в товары можно различными способами. Каждый используемый способ -это отдельная технология по которой производят тот или иной товар.

В зависимости от того в какой сфере деятельности используется та или иная технология может иметь разные приоритеты и назначения. Следовательно, возникает необходимость классификации технологий в зависимости от определенных признаков: динамичность, точность, последовательность, гибкость.

Принцип динамичности заключается в постоянном развитии предприятий, выполнении каких-либо действий, движений и процессов, при этом повышаются требования к сотрудникам предприятия, ставятся перед ними всё более сложные и сложные задачи.

Принцип точности - характеризуется степенью приближения каждого бизнес-процесса к главному общему результату предприятия.

Принцип последовательности заключается в рациональном размещении рабочих мест на предприятии, т.е. логической увязки определенных процессов, связывающих стратегию с действиями на каждом уровне организации направленных на достижение цели. Известные теоретики Леон Фестингер, Фриц Хайдер и Теодор Ныокомб считают стремление к последовательности главным мотиватором человеческого поведения. При этом каждому руководителю важно учитывать обязательства между функциями и бизнес-единицами и возможность координации действий между подразделениями предприятия. 
Принцип гибкости заключается в способности предприятия быстро адаптироваться к требованиям рынка. Гибкие технологии - это совокупность методов и приёмов управления всеми совокупными ресурсами предприятия, позволяющие реализовывать проектные цели предприятия наиболее эффективным способом.

В отчёте о росте мирового проектного управления Industry Growth Forecast Report от Project Management Institute (PMI) в 2013 г. говорится, что в период между 2010 и 2020 годом в мире появится 15,7 миллионов новых «проектных ролей», которые создадут семь основных проектно-ориентированных отраслей. К проектно-ориентированным отраслям отнесены: производство и обрабатывающая промышленность, бизнес-услуги, финансовый и страховой сектор, нефтегазовый сектор, информационные технологии, строительство, коммунальные услуги и недвижимость. Как показала практика, экспертные прогнозы сбываются, масштабы проектной деятельности растут. К проектно-ориентированным отраслям, кроме названных, можно отнести государственное и муниципальное управление, цифровые технологии и производство цифровой техники. По данным компании «TwentyEighty», 74\% организаций Америки и стран Европы имеют проектный офис, половина из них имеют пять офисов или более [5].

Особенностью проектного управления заключается в том, что цели проекта ограничены в количестве, в средствах и во времени. Разрабатывая стратегию реализации того или иного проекта, руководители предприятий составляют подробные сметы, дорожные карты, чек-листы в которых детально прописывают функционал каждого сотрудника и объём ресурсов, приходящихся на одного участника проекта. Но к сожалению, как бы детально не составлялся стратегический план развития предприятия (выполнения проекта), всегда возникают непредвиденные события, которые могут помочь или помешать предприятию в достижении стратегических целей.

Руководители структурных подразделений на всех уровнях управления должны молниеносно реагировать на воздействующие как внешние, так и внутренние факторы на местах, преодолевать неожиданные сложности и использовать благоприятные возможности для компании. Если руководители могут использо- вать такие возможности или быстро реагируют на неожиданное сложности, своими действиями они не отходят от стратегической цели проекта и не нарушают дорожную карту проекта, а лишь показывают исполнение проекта в лучшем виде.

Все эти корректировки, которые происходят в реальном времени требуют использования гибкости управления от предприятия, т.е. способности и готовности экспериментировать с новой бизнес-моделью. Использование Agile в структурные подразделения предприятия таких как служба управления персоналом, маркетинг, логистика, закупка, сбыт и другие службы, позволяет внедрить совершенно новые нестандартные подходы к организации работы в областях и за пределами информационных технологий (ИТ), для которых создавались. «Умные организации» понимают это - они внедряют Agile у себя и ищут возможности для расширения его применения. Рассмотрим популярные разновидности гибких технологий управления (agile методологий) и дадим их классификацию [6].

Методология Scrum (англ. scrum «схватка») метод управления проектами, при котором основной акцент делается на качестве контроля за ходом работы. Несмотря на то, что методология Scrum является гибкой, но роли между участниками проекта можно распределить следующим образом (рисунок 1$)$.

Гибкая методология Scrum, как и любой метод управления имеет свои достоинства и недостатки. Достоинствами являются:

- прозрачность, т.е каждый член проекта несёт ответственности за достижение общей цели, всегда в курсе за процессом выполнения работ и имеет достоверную информацию о сроках выполнения работ;

- самостоятельность членов проекта, т.е участники вправе сами решать, как работать над проектом, какие технологии использовать;

- скорость выполнения проекта, так как заказчик напрямую работает со всеми членами проекта, что позволяет вносить изменения в проект по требованию заказчика.

Недостатками данного метода являются:

- очень тяжело подобрать самоорганизующуюся команду профессионалов способных правильно расставить приоритеты и выполнить задачи;

- сложно внедрить в крупные проекты.

Методология Lean (от англ. lean production, 


\section{Методология Scrum}

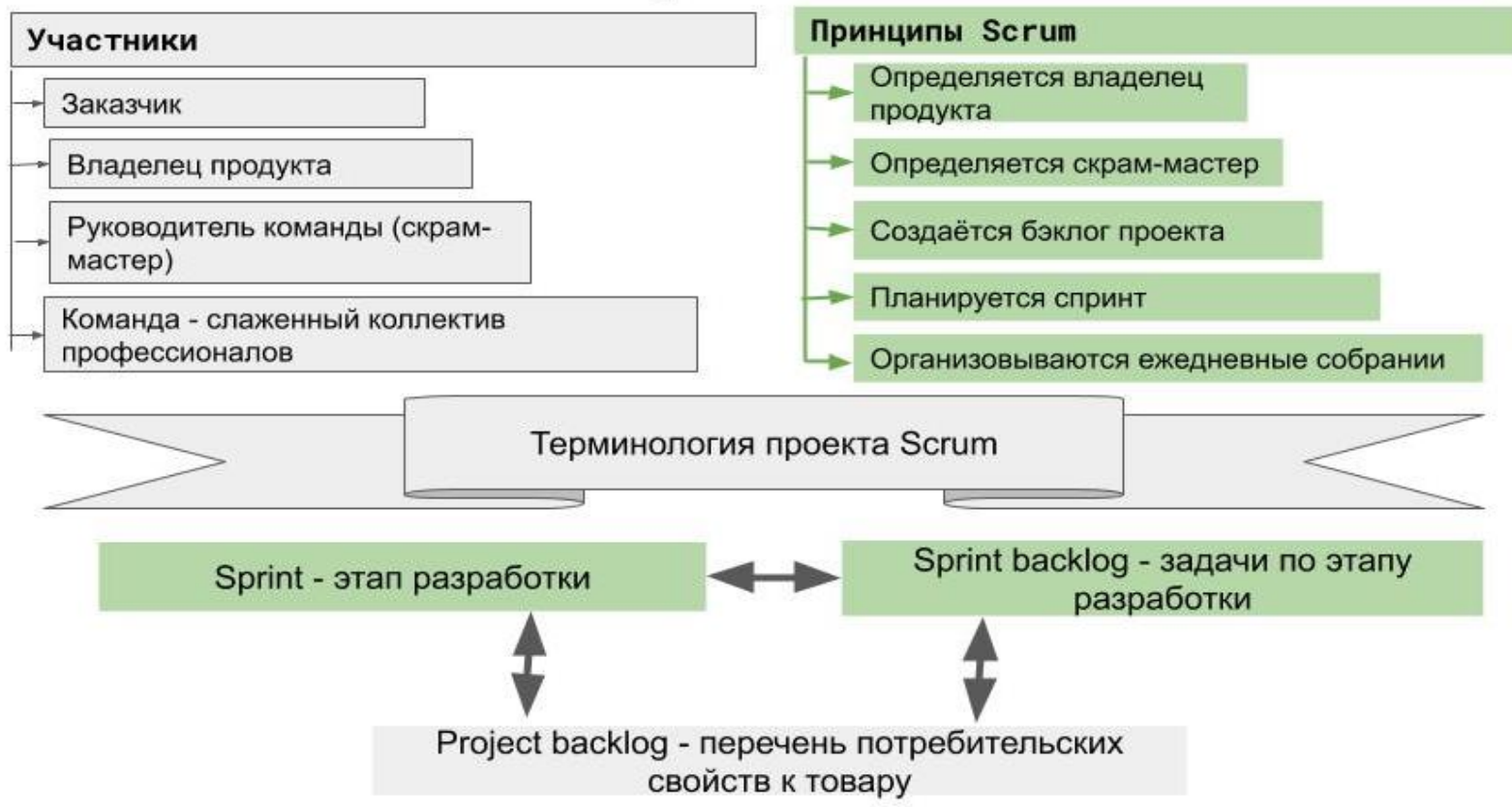

Рисунок 1. Гибкая методология Scrum

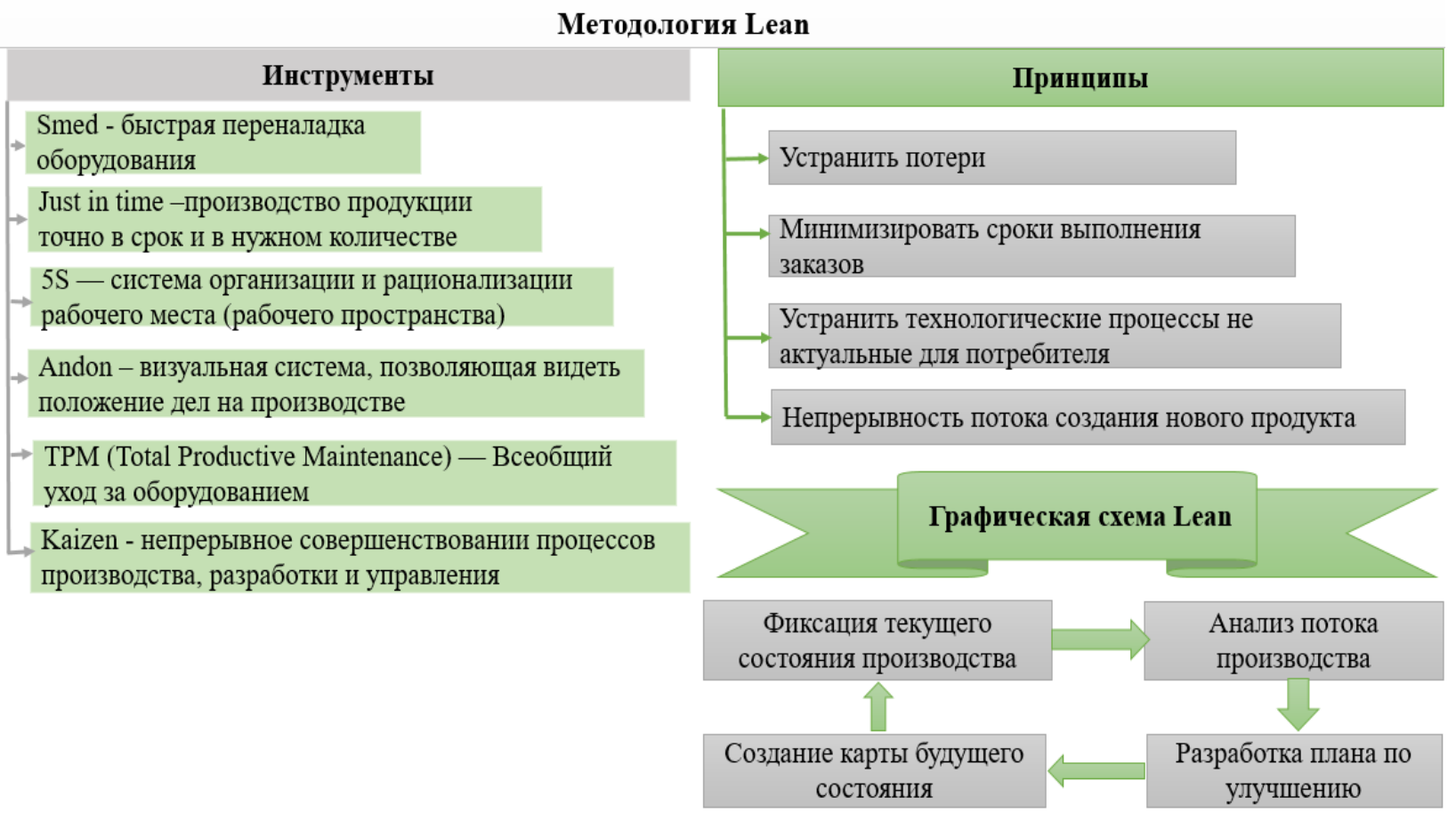

Рисунок 2. Гибкая методология Lean 
lean manufacturing, lean software development «бережливое производство») представляет собой концепцию управления производственным предприятием, которая основана на непрерывном стремлении устранения различных видов потерь, предполагает вовлечение в процесс оптимизации бизнеса всех сотрудников, а также нацелена на максимальную ориентацию на клиента. Гибкая методология Lean представлена на рисунке 2 [8].

Основными преимуществами бережливого производства являются:

1) Экономия времени и денег за счёт снижения затрат на каждом этапе производства.

2) Контроль качества.

3) Сохранение места производства и его постоянное совершенствование.

Недостатки гибкой методологии Lean:

1) Большая зависимость от работы поставщиков

2) Высокая стоимость внедрения.

3) Недовольство со стороны персонала.

4) Неудовлетворенность потребителей, в случае нарушения цепочки поставок. [7]

Шесть сигм (англ. six sigma) - концепция управления производством, которая выражается в необходимости улучшить качество выходов каждого бизнес процесса, минимизировать дефекты и статистические отклонения в операционной деятельности предприятия. Гибкая методология шесть сигм представлена на рисунке 3

Гибкая методология шесть сигм очень хорошо сочетается с методологий Lean. [4] Она также имеет достоинства:

- основное внимание уделяется запросам потребителя;

- даёт возможность внедрения статистического управления;

- позволяет формально представить обязательства руководителей предприятия, планировать распределение средств и контролировать их использование.

И недостатки:

- не объясняет связь между длительностью процессов и качеством проектов удовлетворяющих потребителей;

- отсутствие удовлетворенности у сотрудников от выполненной работы, так как совершенству нет предела;

- высокие издержки при работе над единичными проектами.

Методология PRINCE 2 (проекты в контролируемых средах) - подход к управлению проектами основанный на организации и контроле

\section{Методология Six Sigma}

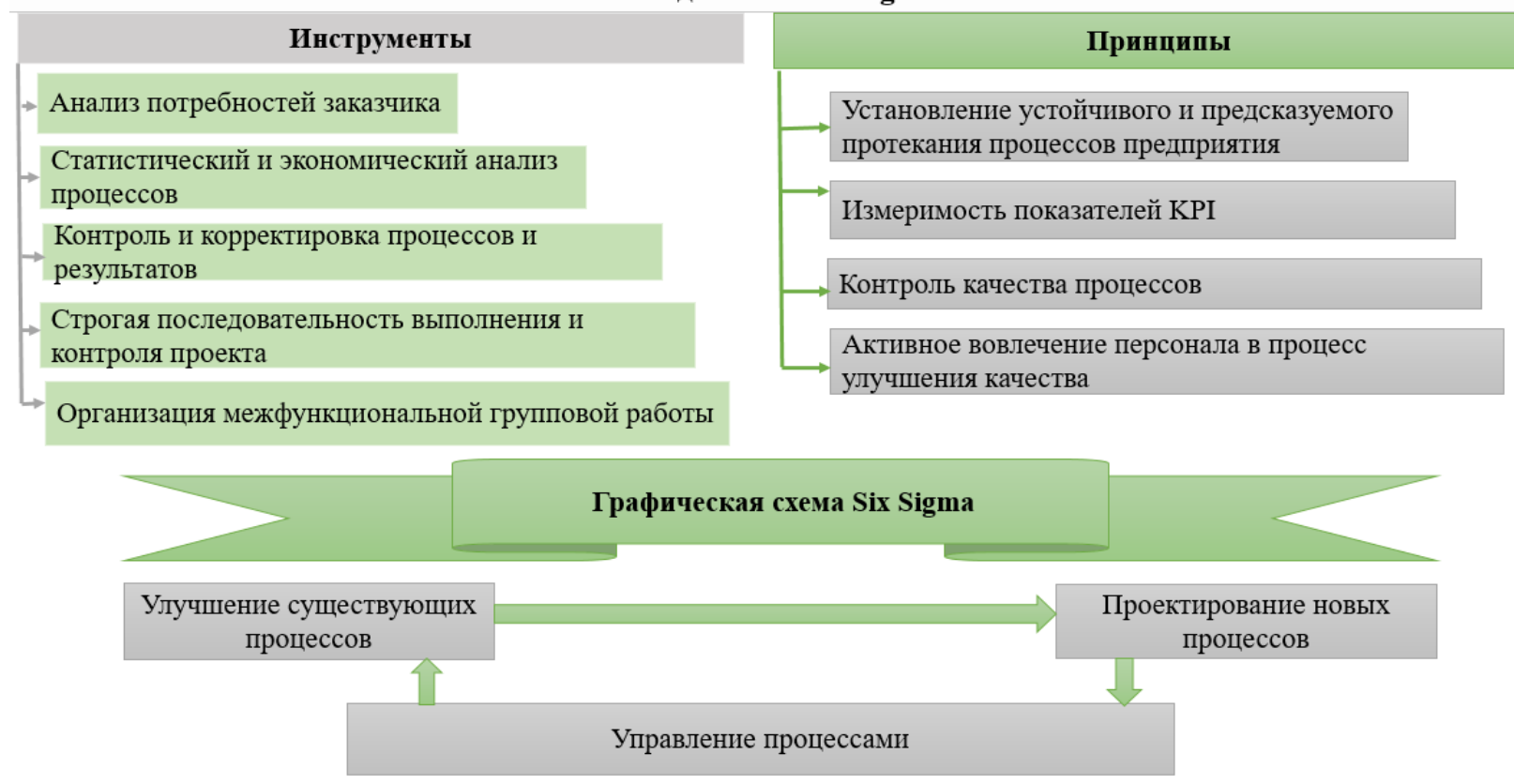

Рисунок 3. Гибкая методология Six Sigma 
над всеми проектами от стадии планирования до стадии полного завершения (рисунок 4).

Основные преимущества данной методологии:

- подходит как для не больших, так и для крупных проектов, где осуществляется постоянный контроль как со стороны руководства, так и со стороны государства;

- структурированность всех бизнеспроцессов проекта;

- учёт опыта и постоянное его совершенствование.

Недостатки методологии PRINCE 2:

- отсутствие инструментов для работы в проекте;

- большое количество отчётов;

- слабая мотивация основных участников проекта. [2]

Рассмотрим в таблице 1 гибкие технологии управления и дадим их классификацию.

Таким образом, гибкие методологии Agile на сегодняшний день активно используются в разных отраслях деятельности предприятий. Чтобы реализовать любой проект, вам обязательно придется что-то менять, искать новые решения, генерировать необычные идеи. Только адаптируясь к постоянно меняющиеся условиям среды, труда и требованиям клиентов, можно найти правильный путь для продолжения работы. Именно гибкая методология управления проектами Agile может стать верным помощником в этом вопросе. Небольшие проектные команды максимизируют эффективность с помощью гибкой Agile методологии.

В заключении сделать вывод, что выбор между традиционным и гибким менеджментом ложится на плечи руководителей компаний, которые, изучив объём работ, конечные цели, квалификацию персонала, оценив объём имеющихся ресурсов, выбирают тот метод, который считают наиболее эффективным. Новые методы и технологии их внедрения - это своего рода вызов коллективу, а как добиться большей эффективности всегда дело индивидуальное. Agile - это не панацея и не гарантия успеха, но она позволяет задать правильный курс и найти ориентиры на этом пути.

Исследования выполнены при финансовой поддержке РФФИ в рамках научного проекта № 20-010-00459\20

\section{Методология PRINCE 2}
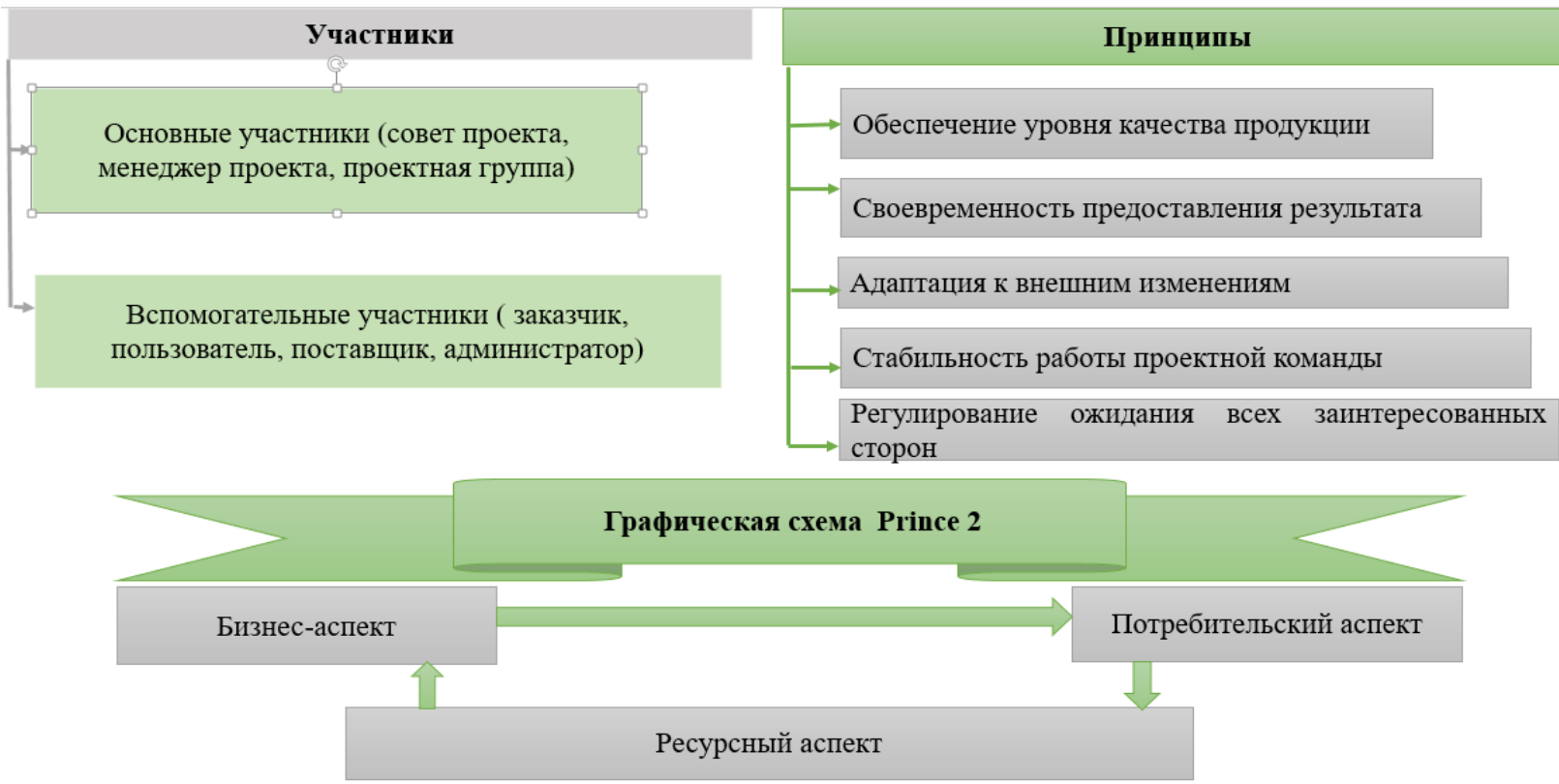

Рисунок 4. Гибкая методология PRINCE 2 
Таблица 1. Классификации agile методологий

\begin{tabular}{|c|c|}
\hline $\begin{array}{l}\text { Наименование } \\
\text { признака }\end{array}$ & Разновидности гибких технологий управления \\
\hline \multicolumn{2}{|r|}{ В зависимости от вида компании, в которых они используются } \\
\hline \multirow[t]{4}{*}{ IT -компании } & $\begin{array}{l}\text { Экстремальное программирование (англ. Extreme Programming (XP)) гибкая } \\
\text { методология разработки программного обеспечения (ПО), адаптированная к } \\
\text { постоянно меняющимся требованиям к программному продукту, основной целью } \\
\text { является повышение качества разработки (поднять их на новый «экстремальный» } \\
\text { уровень). Основное внимание сконцентрировано на четырех процессах: кодирова- } \\
\text { ние, тестирование, планирование, слушание. }\end{array}$ \\
\hline & $\begin{array}{l}\text { Crystal Methodologies (англ. «кристаллические методологии») гибкий подход к } \\
\text { разработке ПО, фокусирующийся на людях и их взаимодействии при работе над } \\
\text { проектом, включает: частую доставку, личные коммуникации и усовершенствова- } \\
\text { ние через рефлексию. }\end{array}$ \\
\hline & $\begin{array}{l}\text { Feature Driven Development (FDD, разработка, управляемая функциональностью) } \\
\text { представляет собой итеративную гибкую методологию аgile разработки ПО, объе- } \\
\text { диняет методики разработки ПО, где за основу принимается важная для заказчика } \\
\text { (конечного потребителя) функциональность (свойства) разрабатываемого ПО. } \\
\text { Основная цель - разрабатывать регулярно, в определенные сроки реальное, рабо- } \\
\text { тающее ПО. }\end{array}$ \\
\hline & $\begin{array}{l}\text { ICONIX это методология разработки программного обеспечения, сфокусированная } \\
\text { на анализе требований и моделировании. }\end{array}$ \\
\hline \multirow[t]{5}{*}{$\begin{array}{l}\text { Производственные } \\
\text { предприятии }\end{array}$} & $\begin{array}{l}\text { Методология Lean (от англ. lean production, lean manufacturing, lean software } \\
\text { development «бережливое производство») }\end{array}$ \\
\hline & $\begin{array}{l}\text { Канбан (япон. カンバン камбан «рекламный щит, вывеска») - систему организа- } \\
\text { ции производства и снабжения, которая позволяет реализовать принцип «точно } \\
\text { в срок». Данная методология обеспечивается за счет максимальной прозрачности } \\
\text { процесса разработки и равномерного распределения работы между всеми участни- } \\
\text { ками проектной команды, также способствует усилению сотрудничества, стремле- } \\
\text { нию совершенствовать знания, навыки, умения и активно развиваться }\end{array}$ \\
\hline & Шесть сигм (англ. six sigma) \\
\hline & $\begin{array}{l}\text { Dynamic Software Development Method (DSDM) (англ. динамический метод раз- } \\
\text { работки программного обеспечения) представляет собой методику разработки ПО, } \\
\text { построенную на быстрой разработке приложений, при этом огромное значение } \\
\text { отведено длительному участию в процессе пользователя (конечного потребителя } \\
\text { услуги). Основной цель данного метода является сдача готового проекта в срок, } \\
\text { при определенном бюджете, но при этом существует возможность регулировать } \\
\text { изменения требований к конкретному проекту во время его непосредственной } \\
\text { разработки. }\end{array}$ \\
\hline & $\begin{array}{l}\text { Quick Response Manufacturing (QRM) (англ. быстрореагирующее производство) } \\
\text { основное внимание сфокусировано на сокращении времени выполнения заказа } \\
\text { (проекта) при введении показателя, называемого критический производственный } \\
\text { путь (КПП), то есть самый длинный отрезок времени, который охватывает время } \\
\text { от начала производства конкретного изделия до окончания производства всего } \\
\text { заказа, называемый временем производственного цикла изделия. }\end{array}$ \\
\hline \multirow{4}{*}{$\begin{array}{l}\text { Торговые компании } \\
\text { (рекрутинговые, кон- } \\
\text { салтинговые, марке- } \\
\text { тинговые, PR, бухгал- } \\
\text { терские фирмы и т.д) }\end{array}$} & Методология Scrum (англ. scrum «схватка») \\
\hline & $\begin{array}{l}\text { Коучинг (англ. coaching «тренер, наставник, инструктор») метод консалтинга и } \\
\text { тренинга, который способствует помощи обучающемуся достичь определенной } \\
\text { профессиональной, жизненной цели, а также направлен на достижение конкрет- } \\
\text { ных инструктор») целей (например, проекта) взамен общего развития. }\end{array}$ \\
\hline & $\begin{array}{l}\text { Trello представляет собой систему управления проектами в режиме онлайн по } \\
\text { методу японских канбан-досок, способствует наиболее тесному взаимодействию } \\
\text { и увеличению эффективности работы за счет упорядочивания проектов и расста- } \\
\text { новки приоритетов, а также возможность вести контроль большого количества } \\
\text { проектов одновременно. }\end{array}$ \\
\hline & $\begin{array}{l}\text { Crystal Clear - это легковесная гибкая методология, предназначена для небольших } \\
\text { команд в 6-8 человек для разработки некритичных бизнес-приложений, опираю- } \\
\text { щаяся больше на людей, чем на процессы и артефакты }\end{array}$ \\
\hline
\end{tabular}




\begin{tabular}{|c|c|}
\hline \multicolumn{2}{|c|}{$\begin{array}{c}\text { В зависимости от хронологии возникновения комплексов гибких методов разработки ПО, } \\
\text { способных заменить сложные и трудоемкие методы }\end{array}$} \\
\hline 1991 год & метод быстрой разработки приложений RAD \\
\hline 1994 год & метод разработки динамических систем DSDM \\
\hline 1995 год & платформа (фреймворк) гибкой разработки Scrum \\
\hline \multirow{2}{*}{1996 год } & гибкая методология разработки Crystal Clear \\
\hline & экстремальное программирование XР \\
\hline 1997 год & итеративная методология разработки ПО FDD \\
\hline 2001 год & Манифест о гибкой разработке программного обеспечения Agile \\
\hline 2004 год & Crystal Clear \\
\hline 2009 год & $\begin{array}{l}\text { Test Driven Development - разработка через тестирование или разработка через } \\
\text { тесты }\end{array}$ \\
\hline 2011 год & $\begin{array}{l}\text { Модель CDE (Container/Differences/Exchanges) представляет собой простой фрейм- } \\
\text { ворк для развития самоуправляемых команд }\end{array}$ \\
\hline \multicolumn{2}{|r|}{ В зависимости от практик экстремального программирования } \\
\hline \multirow{3}{*}{$\begin{array}{l}\text { Управленческие } \\
\text { практики }\end{array}$} & Crystal Clear \\
\hline & Scrum \\
\hline & Модель CDE (Container/Differences/Exchanges) \\
\hline \multirow[b]{2}{*}{ Инженерные практики } & Dynamic Systems Development Method (DSDM) \\
\hline & $\begin{array}{l}\text { Test Driven Development - разработка через тестирование или разработка через } \\
\text { тесты }\end{array}$ \\
\hline \multirow{2}{*}{$\begin{array}{l}\text { Организация поддерж- } \\
\text { ки }\end{array}$} & $\begin{array}{l}\text { ICONIX - это методология разработки программного обеспечения, сфокусирован- } \\
\text { ная на анализе требований и моделировании. }\end{array}$ \\
\hline & Extreme Programming (XP) \\
\hline \multirow{3}{*}{$\begin{array}{l}\text { Оптимизация произ- } \\
\text { водства }\end{array}$} & Dynamic Systems Development Method (DSDM) \\
\hline & Канбан \\
\hline & Методология Lean \\
\hline \multicolumn{2}{|r|}{ В зависимости от методологии управления разработкой ПО } \\
\hline $\begin{array}{l}\text { Традиционные или } \\
\text { каскадные модели }\end{array}$ & Предполагает последовательное выполнение всех фаз проекта \\
\hline Спиральная модель & $\begin{array}{l}\text { Представляет собой цикл (спираль) начинающийся с этапа сбора требований к } \\
\text { предполагаемым изменениям и завершающиеся реализацией прототипа. }\end{array}$ \\
\hline Итеративная модель & $\begin{array}{l}\text { Предполагает разработку проекта как последовательность итерации, каждая из } \\
\text { которых сама по себе является небольшим проектом для достижения общей задачи }\end{array}$ \\
\hline
\end{tabular}

Источник: Составлено авторами

\section{Библиографический список}

1. Бабанова, Ю.В. Гибкие технологии управления предприятием в условиях цифровизации экономики / Ю.В.Бабанова, В.М.Орлов, Р.С.Антонян // Известия Волгоградского государственного технического университета.-2018. - № 6 (216).- С. 61-66.

2. Клименко Э. Ю. Трансформация управления проектами в цифровой экономике/ Э. Ю. Клименко // Управление проектами и программами. 2018. № 2. С.110-117.

3. МироненкоА.С../ Гибкие технологии управления современными организациями // А.С.Мироненко, Г.В.Сковороднева, О.В.Дымченко /: Современные проблемы управления и экономического развития. сборник статей по материалам Международной научно-практической конференции. Министерство науки и высшего образования Российской Федерации, Донской государственный технический университет. 2019. С. 158-162.

4. Раева Т.Д.Практика применения гибких технологий в управлении развитием предприятий в условиях цифровой трансформации бизнеса/ Т.Д.Раева // В сборнике: Цифровая экономика промышленности и сферы услуг: состояние и тенденции развития. Труды XVI научно-практической конференции с международным участием. Под редакцией А. В. Бабкина. 2018. С. 413-420. 
5. Романенко М.А. Влияние гибких технологий на управление человеческими ресурсами проектов предприятий/ М. А. Романенко, С. Н. Апенько // Фундаментальные исследования. - 2016. - № 9-2. - C. 411-418; URL: http://www.fundamental-research.ru/ru/article/view?id=40759 (дата обращения: 14.07.2020).

6. Чуланова, О.Л.Технология управления проектами и проектными командами на основе методологии гибкого управления проектами Agile/ О. Л. Чуланова // Вестник Евразийской науки, 2018 № 1, https:/esj.today/ PDF/65ECVN118.pdf (доступ свободный). Загл. с экрана. Яз. рус., англ.

7. Шестакова, E.B. Появление и необходимость применения гибких технологий управления в деятельности современных предприятий в условиях изменения внешней среды / Е.В Шестакова, А.М.Ситжанова, P.М.Прытков //Современные тенденции и технологии развития потенциала регионов: сборник статей первой национальной научно-практической конференции (24 апреля 2020 года, г. Санкт-Петербург).СПб: ЧОУ ВО «Санкт-Петербургский университет технологий управления и экономики», 2020.- С. 44-50 с.

8. Шестакова, E.В.Гибкие технологии управления: сущность, принципы, ценности и преимущества [Электронный ресурс] / Е. В.Шестакова, А. М. Ситжанова, Р. М.Прытков // Финансовая экономика, 2020.- № 5.C. 317-321.

9. Kumar, Singh, Jain Agile manufacturing: a literature review and Pareto analysis / Kumar, Singh, Jain// International Journal of Quality and Reliability Management - 2019. - № 37 - pp. 207-222.

10. Waddington T. Lean and agile supply chain design. Littoralis.info. [Электронный ресурc]. URL: http://www. littoralis.info/iom/secure/assets/iom_iom20031201.236634_3fe 97d8a17e03.pdf. 